\title{
CONSIDERACIÓS ENCOL DO TRABALLO DE DON AQUILINO IGLESIAS ALVARIÑO: A LINGUA GALLEGA - HISTORIA DO SEU VOCABULARIO
}

DOI: 10.17057/fmfhv.2021.017

Informe elaborado en Buenos Aires, a instancias de Manuel Puente, por "amigos patriotas» dos que non constan os nomes. Chegou a Trasalba acompañando, no mesmo envío, a carta anterior. Está dixitalizado e integrado no Fondo Fundación Manuel Puente, do Consello da Cultura Galega. 

Estímase que iste traballo, nembargantes seu outo prestamento, non é o axeitado pra Historia de Galicia que se ven facendo apadriñada por D. Manuel Puente. Atópase fallarlle a quentura patriótica que lóxicamente corresponde que teña o conxunto da obra, inda que, pola sua condizón, todalas colaboraciós — de maneira especial a de iste tema-, teñan de ser feitas con rixideza téinica e con serea e fidel ouxetividade.

Unha forte paixón patriótica galega foi o que moveu a Don Manuel Puente a custear tan grandeira obra que o inmorrente Castelao entendía ser fundamental pra inxente laboura de concretar os soños de erguemento e redenzón de Galicia. A mesma paixón patriótica moveu tamén a Don Ramón Otero Pedrayo pra coller a seu carrego a pesada tarefa e responsabilidade de dirixir a obra.

Os patriotas galegos estamos empeñados na rexa e trascendental laboura que encetaron os Precursores. A Historia de Galicia, escrita na nosa lingua, ten de ser unha das máis eficaces aportaciós pra o soerguemento da nosa patria. Pra elo, pra que ise aporte seña podente, compre forxalo no fogo patriótico galego.

Até onde non haxe que fallar a verdade, é lícito e faise imprescindibele que todolos traballos de Historia de Galicia teñan forte quentura patriótica que alcenda o esprito dos galegos, que lles enforteza sua persoalidade, os inflame de outimismo e lles dea pulos para traballar a prol da sua patria. E polo que fai as xentes alleas, a nosa Historia ten de levar ao seu ánimo o convencimento e as razós que lle asisten a Galicia pra recramar o dereito a gozar da sua prena persoalidade nazonal, perfeitamente compatibele con unha conxunzón cos demáis povos hespañoes.

O traballo do señor Iglesias [sic] Alvariño, lexos de responder a elo, é certamente de efeutos deprimentes. Deixa no leitor unha ideia de probeza da nosa lingua e de non ser preciso o conservala por estar superada con amplitude pola lingua castelán. Pra o erguemento da persoalidade nazonal galega é básico e imprescindibele o manter e categorizar a nosa lingua. Non se pide caer na parvedade «chauvinista» de procramar a superioridade da lingua galega sobor de 
outras e menos da castelán, na cal temos non pequena pertenza. Mais, non se ten porque faguer comparanzas en perxuizo da nosa. A lingua galega pola soia razón de ser nosa ten pra nós outísima valenza. Si é probe, si se atopa entangarañada, non por elo hemos de renegar de éla. Razón amáis pra lle botar man con amore. Ela é xenuina espresión do noso esprito; por elo nosa obriga ten de ser o mantela, fortecela e doarlle esprendor. Sen ela a persoalidade galega ficará sempre esmalloada. Mais, felismente, non é tan probe... Ben que lle serviu o mesmo señor Iglesias Alvariño para traducir a Horacio...!

O traballo en custión fai cavilar en que non foi feito pra ser capitol da parte limiar da Historia de Galicia. Por repentenexo que sexa o autor, se non concebe que fixer ise traballo de xeito especial pra unha obra de alento patriótico galego, como ten de sere isa, dándolle o ton «derrotista» que o carauteriza. De habelo feito a mantenta pra Historia de Galicia, obra destiñada a xentes de tuda crás, e non pra estudantes de filoloxía en particular, cecáis puxera n-íl máis senso patriótico galego que erudición téinica. Ben se pode dicir que ise traballo mesmo parescera feito por un filólogo hespañol como capitol encol da lingua galega destiñado a unha obra de téinica linguística de eisaltazón do idioma castelán. Somentes esí se esprica o xeito parvo de desprezar ao idioma portugués («tu que non podes lévame as costas») que se atopa na liña 19 da páxina 27. Somentes esí se esprican as crúas manifestaciós que fai o señor Iglesias Alvariño na páxina 5 de franco devaler — que chega até o desprezo- da lingua galega. Isto pra un leitor corrente, como será a maoría dos que leian a Historia de Galicia. Os sabidos, os especializados, os filólogos poderán interpretar con friaxe e fidelmente as afirmaciós encol da causal evolutiva da nosa lingua que se fan na dita páxina. Mais, a Historia de Galicia non se fai somentes pra ise núcreo... Pra o caso, é cecáis o núcreo que menos intresa. E perdóese a irreverenza...! Canto se dí na devandita páxina No 5 -inda sendo rigurosamente certo no orde filolóxiconon é do caso poñelo de bulto nunha obra como a Historia de Galicia, que ten unha lóxica finalidade de eisaltazón patriótica. O feito mesmo de termos unha lingua emprobecida de resultas da detenza que sofreu no seu desenrolo, lingua que istán percurando heroicamente erguer e vitalizar os escritores de paixón patriótica galega, sería razón de abondo pra o non consinar nunha obra tal. Ise escrarecemento téinico linguístico poderá istar ben que se faga cando o idioma galego sexa xa barudo e se teña erguido a un outo prano. Que sexan entón os 
novos Iglesias Alvariño quenes se luzan con laboura tan cativa no orde patriótico galego. Daquela, o millor, será de máis lucimento o escrarecer o arrequentamento da lingua castelán con verbas galegas...

Moito máis se podería apontar encol de tan desaxeitado traballo, como ser a cantidade de castelanismos do que istá pragado (a mesma tendenza se adevirte na traduzón de Carmina). Castelanismos que poden en pura lei filolóxica, non seren taes, ou seren verbas comúns aos idiomas galego e castelán, pro que no afebramento do traballar pra ceibar a nosa lingua das podentes poutas da lingua castelán é patriótico o desbotalas en tudolos casos nos que taes verbas podan seren supridas por outras de craro enxebrismo galego. De non, a nosa singularidade literaria desenrolaríase esmaiolada e sen pulo. Semellaría ser o galego un satélite dormente do castelán.

Dende logo, fique ben craro que istes reparos ao traballo do señor Iglesias Alvariño son somentes de caraute patriótico, de comenencia e dinidade patriótica galega. Sostemos non é axeitado pra unha obra ca finalidade, pra unha obra «comprometida» como ten de sere a Historia de Galicia. Pois, polo demáis, estamos lonxe de subestimar ise traballo. Anque horfos de autoridade filolóxica e de erudizón linguística non deixamos de enxergar sua outa xerarquía e sua estraordinaria valenza nises ordes. E acochamos a seguridade de que o señor Iglesias Alvariño, imposto das ouservaciós que se deixan espresadas, terá de comprender e aprezar as inquedanzas e ciumes patrióticos que as ditaron e que, polo tanto, sentíndose solidario con ises nobres sentimentos lle á ser doado o axeitar seu traballo ao esprito e finalidade da Historia de Galicia.

\section{ALGUNHAS VERBAS DO TRABALLO DE IGLESIAS ALVARIÑO QUE POIDERAN SUPRIRSE AO NOSO VER CON VERBAS GALEGAS}

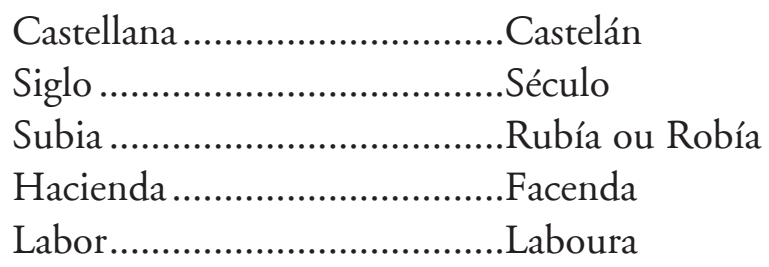




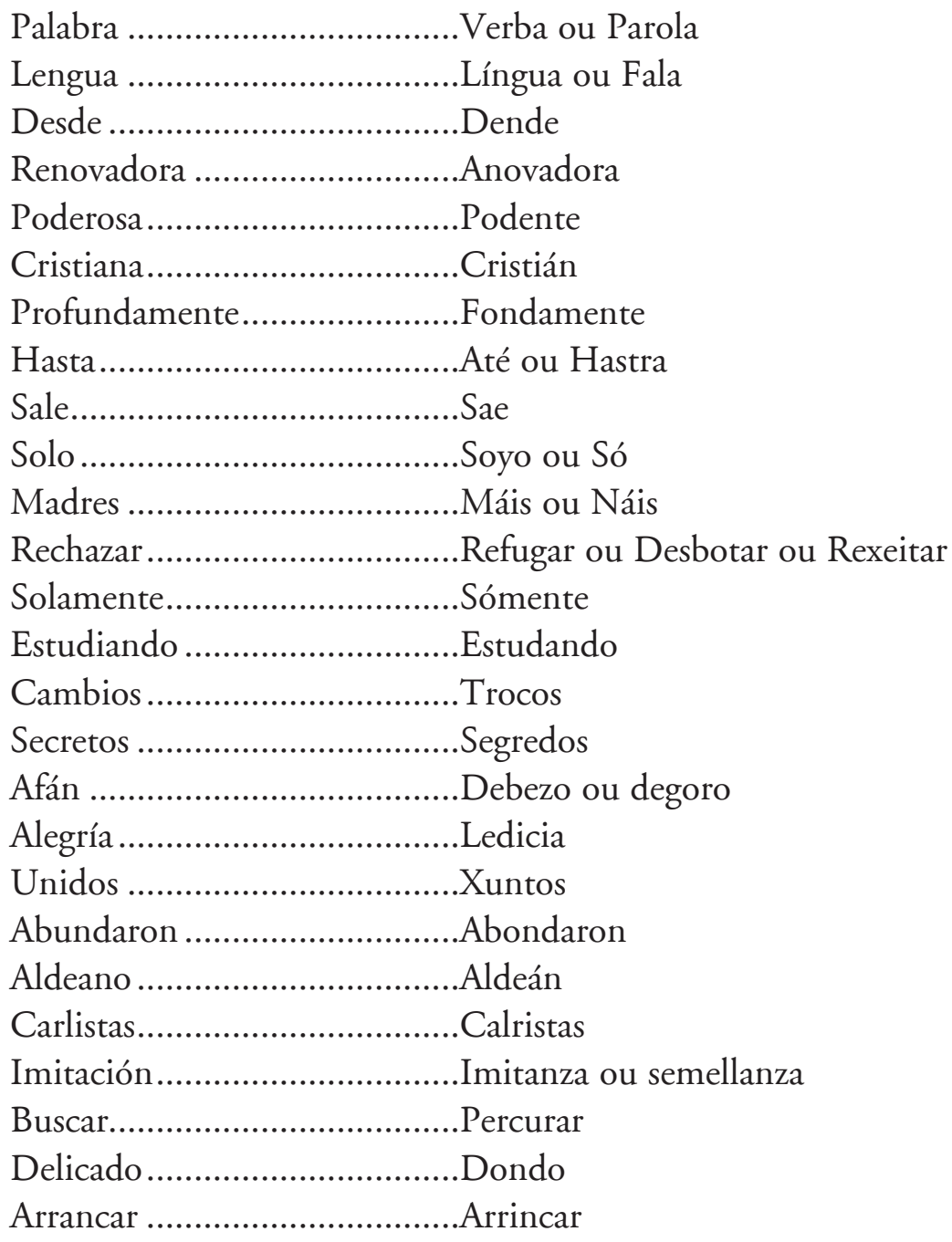

A verba Gallego, xa se dí na carátula do traballo que se supra por Galego. Si o autor aceitou ise troco, non podería facer o mesmo cas demáis verbas castelás? 